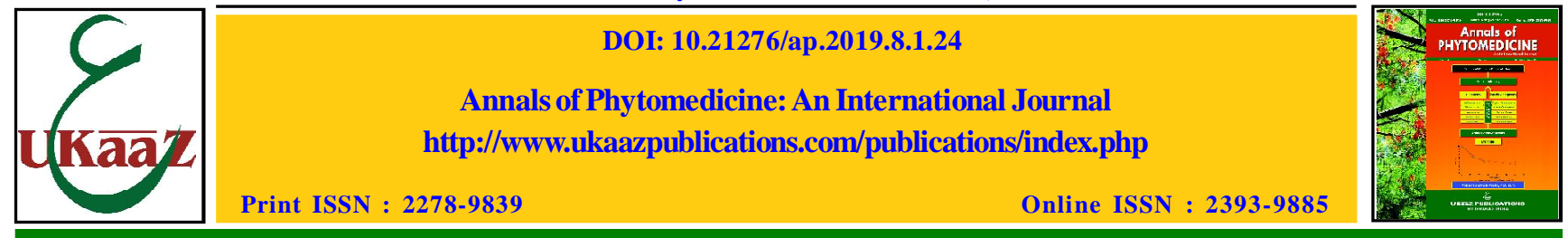

Original article

\title{
Evaluation of pathophysiological alterations in rats administered with marbofloxacin alone and with piperine pretreatment
}

\author{
Vipul B. Chauhan, Chirag M. Modi`, Harshad B. Patel and Urvesh D. Patel \\ Department of Pharmacology and Toxicology, College of Veterinary Science and Animal Husbandry, Junagadh \\ Agricultural University, Junagadh-362001, Gujarat, India
}

Received January 4, 2019: Revised February 24, 2019: Accepted February 28, 2019: Published online June 30, 2019

\begin{abstract}
The present study was conducted to evaluate pathophysiological alterations after repeated oral administration of marbofloxacin alone and along with piperine pretreatment in rats. Blood samples were collected from treated animals at $6^{\text {th }}$ day. Hematological parameters (Hb, PCV, TLC, TEC, DLC, MCV, MCH and MCHC) and serum biochemical parameters (ALT, AST, total protein, albumin, globulin, LDH, creatinine, BUN, bilirubin and AKP) were estimated after five days treatment. Hematological and serum biochemical parameters were not found influenced after treatments and their mean values were not significantly altered $(p>0.01)$ from corresponding control values. Moreover, no gross or microscopic changes were found in all major organs except liver of the treated rats. The histopathological changes in liver of treatment groups II (marbofloxacin alone) and III (marbofloxacin with piperine pretreatment) revealed mild degree of congestion and vacuolar degeneration in hepatocytes. It was concluded that piperine pretreatment for $5^{\text {th }}$ day in rats did not produce significant pathophysiological alterations in blood, serum biochemical parameters and microscopic changes in major organs with absence of clinical signs of side effects, following repeated oral administration of marbofloxacin.
\end{abstract}

Keywords: Piperine, marbofloxacin, pathophysiological alterations and rats

\section{Introduction}

The fluoroquinolones are the fastest growing antibacterial class in terms of global revenue, which is used in dairy animals to treat a wide range of infectious diseases (Bhanot et al., 2001). Marbofloxacin is a bactericidal and a fourth-generation fluoroquinolone having broad spectrum of antimicrobial activity against gram-negative, gram-positive bacteria and also effective against anaerobes and atypical organism such as Mycoplasma and Chlamydia spp. which are exclusively used in veterinary medicine (Brown, 1996). In vivo and in vitro efficacy of marbofloxacin against Staphylococcus intermedius, Escherichia coli, Proteus mirabilis, Pseudomonas spp., Pasteurella multocida, and Mannheima haemolytica have been reported (Spreng et al., 1995; Shojaee and Lees, 1997). Pharmacokinetic of marbofloxacin suggests good tissue penetration. Its broad-spectrum activity is useful for the treatment of respiratory, urinary tract and skin infections in domestic animals (Brown,1996; Ihrke et al., 1999). Efficacy of marbofloxacin largely depends on the optimum dosage regimen and safety impact when used alone with other drugs or agent.

In current scenario, herbal medicines with drugs are used frequently and their clinically relevant interactions are increasingly attracting researchers for the sake of public health issues like drug resistance

\footnotetext{
Author for correspondence: Dr. Chirag M. Modi

Assistant Professor, Department of Pharmacology and Toxicology, College of Veterinary Science and Animal Husbandry, Junagadh Agricultural University, Junagadh-362001, Gujarat, India

E-mail: chiragvets@yahoo.co.in

Tel.: +91-9428757409
}

Copyright $\odot 2019$ Ukaaz Publications. All rights reserved.

Email: ukaaz@yahoo.com; Website: www.ukaazpublications.com and safety impact. It might led to an increased risk of herbal drug interactions. The piperine alkaloid derived from pepper has been observed to be a potent enhancer of the bioavailability and therapeutic efficacy of the concurrently administered of various antimicrobial agents like beta-lactams, ciprofloxacin, oxytetracycline, norfloxacin, marbofloxacin and ampicillin (Hiwale et al., 2002; Patel et al., 2018). It exhibits a wide variety of biological effects which include; anti-inflammatory, antioxidant, antidepressant and hepatoprotective activity (Lee et al., 2005; Patel and Shah, 2009; Shaul et al., 2018; Bhadarka et al., 2018; Modi et al., 2018). Piperine protects $\left(10 \mathrm{mg} / \mathrm{kg}^{-1}\right.$, p.o.) against beryllium induced biochemical alteration and oxidative stress in female albino wistar rats (Zhao et al., 2007). Recently, it has also been reported the cytoprotective role of piperine in deltamethrin induced thymocytes apoptosis (Kumar et al., 2015). Keeping this hypothesis in view, piperine can increase bioefficacy which may alter the impact on safety profile of the target compound. However, these studies did not investigate whether increased bioefficacy and safety of the target compound by piperine. Therefore, the present study was planned to evaluate pathophysiological alterations when administered marbofloxacin alone and with piperine pretreatment in rats.

\section{Materials and Methods}

\subsection{Experimental animals}

The present study was conducted on 18 albino rats, procured from Cadila Pharmaceutical Pvt. Ltd., Dholka, Ahmedabad, Gujarat. Healthy rats having body weight between 200-250 gm and age of 89 weeks, were selected for the study. The protocol and number of animals (No. JAU/JVC/IAEC/SA/08/2016) were approved by 
Institutional Animal Ethics Committee, College of Veterinary Science and Animal Husbandry, Junagadh, Gujarat, India, according to the regulation of Committee for the Purpose of Control and Supervision of Experiments on Animals (CPCSEA, 2003).

\subsection{Animal husbandry}

All animals were kept at a controlled temperature $\left(25 \pm 2^{\circ} \mathrm{C}\right)$ with relative humidity of $60-70 \% .12 \mathrm{~h}$ light/dark cycle was maintained. The rats were allowed to acclimatise with for at least one week before the start of the experiment. Standard pelleted feed containing $18 \%$ protein and water were provided ad libitum to animals throughout the study period.

\subsection{Experimental design}

Eighteen albino rats were randomly divided according to body weight into three experimental groups, containing six in each. Rats of group I received distilled water. Rats of group II were treated orally with marbofloxacin alone at dose rate of $5 \mathrm{mg} / \mathrm{kg}$ of body weight for 5 days. Group III were treated with piperine pretreatment $(10 \mathrm{mg} /$ $\mathrm{kg}$, p.o. for 5 days), following marbofloxacin at dose rate of $5 \mathrm{mg} / \mathrm{kg}$ of body weight for 5 days.

\subsection{Collection of samples}

Blood samples from all rats were collected from retro-orbital sinus under light anaesthesia at $6^{\text {th }}$ day for haematological and serum biochemical analysis. Blood smears for determination of differential leukocyte count (DLC) were prepared from fresh blood at the time of blood collection. Blood sample $(1 \mathrm{ml})$ collected in $\mathrm{K}_{3}$ EDTA test tubes, were utilized for haematological evaluation and those collected in non-heparinized test tubes $(1 \mathrm{ml})$ were allowed to clot at room temperature. Serum was separated after centrifugation of blood samples at $4000 \mathrm{rpm}$ for $10 \mathrm{~min}$. The serum samples were transferred to cryo-vials and then stored at $-20^{\circ} \mathrm{C}$ until assayed for enzyme estimation. Major organs were collected at the end of experiment for gross and histological examination for the presence of any pathological lesions.

\subsection{Haemato-biochemical analysis}

Hematological parameters like hemoglobin $(\mathrm{Hb})$, packed cell volume (PCV), total leukocyte count (TLC), differential leukocyte count (DLC), mean corpuscular volume (MCV), mean corpuscular hemoglobin concentration (MCHC) and mean corpuscular haemoglobin $(\mathrm{MCH})$ were analyzed by using automatic hematology analyzer (Abacus Junior Vet 5, Diatron, Hungary). Whereas, DLC was carried out as per the method described by Schalm (1967). The biochemical parameters like aspartate aminotransferase (AST), alanine aminotransferase (ALT), lactate dehydrogenase (LDH), alkaline phosphatase (AKP), creatinine, bilirubin (total), blood urea nitrogen, total protein, albumin and globulin were estimated by automatic biochemistry analyzer (Biosystems S.A., Barcelona, Spain) using standard kits.

\subsection{Histopathology analysis}

Major organs were collected and fixed with $10 \%$ formalin solution. The formalin fixed tissues were subjected to paraffin wax embedding for tissue sectioning. The solidified tissues were cut at 6-8 microns thickness with the help of microtome (Leica Biosystems, Germany) and were stained with haematoxyline and eosin $(\mathrm{H}$ and $\mathrm{E})$ stain (Luna, 1968).

\subsection{Statistical analysis}

All numerical data obtained were presented as Mean \pm standard error (SE). Data were analyzed statistically by Duncan's multiple range tests (DMRT) to the difference in treatment groups (Snedecor and Cochran, 1980).

\section{Results}

In the present study, the effect of piperine on administration of marbofloxacin alone and with piperine pre-treatment in rats were monitored by studying various haemato-biochemical parameters which are presented in Tables 1 and 2, respectively.

Table 1: Effect of daily administration of marbofloxacin following oral $(5 \mathrm{mg} / \mathrm{kg}$ of body weight for 5 days) alone and piperine preconditioning $(10 \mathrm{mg} / \mathrm{kg}$, p.o. for 5 days $)$ on mean values of hematological parameters in rats

\begin{tabular}{|l|r|r|c|}
\hline $\begin{array}{l}\text { Hematological } \\
\text { parameters }\end{array}$ & \multicolumn{1}{|c|}{$\begin{array}{l}\text { Control } \\
\text { group I }\end{array}$} & $\begin{array}{c}\text { Marbofloxacin } \\
\text { alone group II }\end{array}$ & $\begin{array}{c}\text { Marbofloxacin } \\
\text { alone with piperine } \\
\text { pretreated group III }\end{array}$ \\
\hline HB (g/dl) & $14.23 \pm 0.28^{\mathrm{a}}$ & $15.10 \pm 0.265^{\mathrm{a}}$ & $14.97 \pm 0.166^{\mathrm{a}}$ \\
PCV \% & $43.08 \pm 0.83^{\mathrm{a}}$ & $46.82 \pm 0.80^{\mathrm{a}}$ & $46.56 \pm 0.84^{\mathrm{a}}$ \\
TEC $\left(10^{6} / \mu \mathrm{l}\right)$ & $8.85 \pm 0.32^{\mathrm{a}}$ & $8.735 \pm 0.19^{\mathrm{a}}$ & $9.0 \pm 0.11^{\mathrm{a}}$ \\
WBC $\left(10^{3} / \mathrm{cmm}\right)$ & $10.74 \pm 0.69^{\mathrm{a}}$ & $11.86 \pm 0.35^{\mathrm{a}}$ & $10.77 \pm 0.90^{\mathrm{a}}$ \\
Neutrophils $(\%)$ & $17.66 \pm 1.80^{\mathrm{a}}$ & $18.5 \pm 1.89^{\mathrm{a}}$ & $22.33 \pm 2.04^{\mathrm{a}}$ \\
Basophil (\%) & $0.16 \pm 0.16^{\mathrm{a}}$ & $0.00 \pm 0.00^{\mathrm{a}}$ & $0.00 \pm 0.00^{\mathrm{a}}$ \\
Eosinophil (\%) & $1.16 \pm 0.17^{\mathrm{a}}$ & $0.66 \pm 0.21^{\mathrm{a}}$ & $0.50 \pm 0.22^{\mathrm{a}}$ \\
Lymphocyte (\%) & $76 \pm 2.44^{\mathrm{a}}$ & $76.16 \pm 2.15^{\mathrm{a}}$ & $74.66 \pm 2.21^{\mathrm{a}}$ \\
Monocytes (\%) & $5.0 \pm 1.02^{\mathrm{a}}$ & $4.66 \pm 1.11^{\mathrm{a}}$ & $2.5 \pm 0.34^{\mathrm{a}}$ \\
MCV (fl) & $48.5 \pm 0.76^{\mathrm{a}}$ & $53.83 \pm 1.04^{\mathrm{a}}$ & $51.66 \pm 00.9^{\mathrm{a}}$ \\
MCHC (\%) & $31.48 \pm 1.02^{\mathrm{a}}$ & $32.3 \pm 00.3^{\mathrm{a}}$ & $32.16 \pm 0.32^{\mathrm{a}}$ \\
MCH (pg) & $15.35 \pm 0.66^{\mathrm{a}}$ & $17.33 \pm 0.19^{\mathrm{a}}$ & $16.63 \pm 0.19^{\mathrm{a}}$ \\
\hline
\end{tabular}

Values with same superscript in a raw were non-significantly $(p>0.01)$ different. 
Table 2: Effect of daily administration of marbofloxacin following oral $(5 \mathrm{mg} / \mathrm{kg}$ of body weight for 5 days) alone and piperine preconditioning $(10 \mathrm{mg} / \mathrm{kg}$, p.o. for 5 days) on mean values of biochemical parameters in rats

\begin{tabular}{|l|r|r|c|}
\hline $\begin{array}{l}\text { Biochemical } \\
\text { parameters }\end{array}$ & $\begin{array}{c}\text { Control } \\
\text { group I }\end{array}$ & $\begin{array}{c}\text { Marbofloxacin } \\
\text { alone group II }\end{array}$ & $\begin{array}{c}\text { Marbofloxacin alone } \\
\text { with piperine } \\
\text { pretreated } \\
\text { group III }\end{array}$ \\
\hline ALT (IU/l) & $57.27 \pm 2.85^{\mathrm{a}}$ & $57.47 \pm 4.33^{\mathrm{a}}$ & $49.47 \pm 2.99^{\mathrm{ab}}$ \\
AST (IU/l) & $127.62 \pm 6.66^{\mathrm{a}}$ & $155.80 \pm 34.46^{\mathrm{a}}$ & $115 \pm 5.14^{\mathrm{a}}$ \\
Total protein (g/dl) & $7.35 \pm 0.09^{\mathrm{a}}$ & $7.15 \pm 0.12^{\mathrm{a}}$ & $7.46 \pm 0.08^{\mathrm{a}}$ \\
Albumin (g/dl) & $3.61 \pm 0.05^{\mathrm{a}}$ & $3.70 \pm 0.06^{\mathrm{a}}$ & $3.66 \pm 0.11^{\mathrm{a}}$ \\
Globulin (g/dl) & $3.75 \pm 0.11^{\mathrm{a}}$ & $3.548 \pm 0.06^{\mathrm{a}}$ & $3.71 \pm 0.073^{\mathrm{a}}$ \\
LDH (IU/l) & $569.32 \pm 65.62^{\mathrm{a}}$ & $641.80 \pm 110^{\mathrm{a}}$ & $643.33 \pm 53.89^{\mathrm{a}}$ \\
Creatine (mg/dl) & $0.47 \pm 0.01^{\mathrm{a}}$ & $0.518 \pm 0.01^{\mathrm{a}}$ & $0.472 \pm 0.01^{\mathrm{a}}$ \\
Total bilirubin (mg/dl) & $0.09 \pm 0.01^{\mathrm{a}}$ & $00.12 \pm 0.05^{\mathrm{a}}$ & $0.14 \pm 0.02^{\mathrm{a}}$ \\
BUN(mg/dl) & $16.86 \pm 0.58^{\mathrm{a}}$ & $16.63 \pm 0.99^{\mathrm{a}}$ & $19.80 \pm 1.45^{\mathrm{a}}$ \\
AKP $(\mathrm{g} / \mathrm{dl})$ & $21.00 \pm 7.21^{\mathrm{a}}$ & $20.98 \pm 6.71^{\mathrm{a}}$ & $8.78 \pm 34.92^{\mathrm{a}}$ \\
\hline
\end{tabular}

Values with same superscript in a raw were non-significantly $(p>0.01)$ different.

No significant alterations $(p>0.01)$ in all serum biochemical parameters of groups II and III have been observed as compared to that of control (groups I) rats. Mean values of haemoglobin concentration $(\mathrm{g} / \mathrm{dl})$, packed cell volume $(\%)$, total erythrocyte count $\left(\mathrm{x} 10^{6} / \mu \mathrm{l}\right)$ and total leukocyte count $\left(\mathrm{x} 10^{3} / \mu \mathrm{l}\right)$ were not significantly altered $(p>0.01)$ in rats of all groups, when compared to normal control at the end of experiment. Statistically $(p>0.01)$, no alteration was found in $\mathrm{MCV}(\mathrm{fl}), \mathrm{MCHC}(\%)$ and $\mathrm{MCH}(\mathrm{pg})$ between groups II and III treated rats as compared to normal control. No significant $(p>0.01)$ difference was observed in lymphocytes $(\%)$, neutrophils $(\%)$, eosinophil (\%), basophil (\%) and monocytes (\%) in rats of all treatment groups. There was non-significant change in organ weight of all the treatment groups. Normal colour, texture and consistency on gross examination of all major organs of rats were found at the end of experiment. Histopathology of major organs like, liver, kidney, intestine, heart and spleen were evaluated from treatments of all groups. No alterations at cellular level and abnormal microscopic lesion were found in those organs except liver. The histopathological changes in liver of treatment groups II and III revealed mild degree of congestion and vacuolar degeneration in hepatocytes. Both the groups of animals were not showed any local or systemic adverse reactions throughout the study period.

\section{Discussion}

Recently, the importance of natural plant products as alternative medicines has been emphasized by widespread recognition of various health promoting effects. Herbal supplements are becoming more popular and they should be given more attention to potential drug interactions with phytochemicals. Among dietary products, black pepper and long pepper are the most common spices and nutrient enhancers. Piperine, a major active component in black pepper and long pepper, has been reported to enhance drug bioavailability and interactions by altering the pathophysiological parameters (Zhao et al., 2007). Therefore, we have to investigate the effects of piperine on the pathophysiological parameter alteration as in marbofloxacin in rats to reveal the possible interactions.
During the study period, animals of any group did not show any attributable and behavioral changes. Mortality and adverse effects were not observed in any treatment groups throughout the study period. The haemato-biochemical alterations study of marbofloxacin in rats has not reported but safety profile of other fluoroquinolones like ciprofloxacin, enrofloxacin and levofloxacin has investigated in different species of animals by different researchers. Fluoroquinolone is generally well tolerated with mild adverse reactions which are cell limiting in nature and does not require discontinuation of treatment (Ball et al.,1999; Mandell and Tillotson, 2002).

Results of the study are supported by report of non-significant changes in haemato-biochemical parameters, following daily intramuscular administration of marbofloxacin $(2 \mathrm{mg} / \mathrm{kg})$ and trovafloxacin (3 $\mathrm{mg} / \mathrm{kg}$ ) for five days in sheep (Mahmood and Hussein, 2013). Modi et al. (2013a and 2013b) mentioned that, moxifloxacin $(5 \mathrm{mg} / \mathrm{kg}$, b.wt.) did not evok significant differences in hematological and biochemical parameters between pre and post drug treatment period in sheep. The results of the present study are consistent with the same type of study performed in rats by Chauhan et al. (2017), where the effect of piperine on repeated intramuscular administration of marbofloxacin $\left(5.0 \mathrm{mg} / \mathrm{kg}^{-1}\right.$ body weight repeated at $24 \mathrm{~h}$ interval for five days) in wistar rats did not alter (non-significantly) haemato-biochemical parameters.

The results are in agreement with other fluoroquinolones like moxifloxacin when intramuscular injection was given repeatedly by Sadariya et al. (2010) and there was no remarkable alterations in male and female rats. They did not observe remarkable alterations. The same report was also obtained in ciprofloxacin when given repeatedly in calves by intramuscular administration which did not cause any significant alteration in the values of biochemical parameters (Bhavsar et al., 2004). Likewise, Khargharia et al. (2007) have found no alterations in hematological and biochemical 
parameters after repeated intravenous administrations of one of the most widely used fluoroquinolone, enrofloxacin $\left(5 \mathrm{mg} / \mathrm{kg}^{-1}\right.$, repeated at $24 \mathrm{~h}$ for 5 days) in yak. Fluoroquinolones as a class are generally well tolerated; most adverse effects are mild in severity, self-limiting and rarely result in treatment discontinuation (Ball, 1999; Mandell and Tillotson, 2002).

No clinical symptoms were noticed in all treatment groups. Microscopic examination of kidney, heart, lung and intestine except liver revealed no appreciable lesions in rats of all treatment groups (Plates 3-10). Mild degree of congestion and vacuolar degeneration in hepatocytes were noticed in liver of rats of treatment groups II and III (Plates 1-2). The present study revealed the protective potential of piperine by reversing the marbofloxacin altered pathological lesions. Observations of gross and microscopic examination of major organs in the present study are same as the results reported in rats, following repeated oral dose of fandofloxacin (Kim et al., 2003). Likewise, ciprofloxacin was also found safe in cow calves, following repeated administration at dose rate of $5 \mathrm{mg} /$ $\mathrm{kg}$ body weight, no alterations were found in joint cartilage (Bhavsar et al., 2004). However, transient neurological signs and lameness in horses were observed when administered with levofloxacin orally at the dose rate of 15 and $25 \mathrm{mg} / \mathrm{kg}$ for 21 days, but no alterations have been found after 7 days treatment (Alicia et al., 2000). Chunlaratthanaphorn et al. (2007) have found no significant alteration in signs of adverse reaction, behavioral changes, mortality, altered gross appearance or histopathological changes of internal organs by evaluated acute $(5,000 \mathrm{mg} / \mathrm{kg}$ body weight $)$ and subchronic $(300,600$ and $1,200 \mathrm{mg} / \mathrm{kg}$ body weight) toxicities of the water extract from the dried fruits of Piper nigrum L. in either male or female rats. It indicates that repeated oral administration of piperine in rats were well tolerated.

In most of the parts of the world, many herbals are used as cytoprotective agents. Piperine is a well known herbal alkaloid, which acts as a cytoprotective (Kumar and Sharma, 2015; Sankar et al.,2012). Piperine preconditioning with marbofloxacin of rats showed a slight increase in body weight as compared to marbofloxacin alone, which indicates the appetite inducer and antistress effect of herbal. The result of present findings have shown that piperine treatment prevents the alteration of serum biochemical enzymes and histopathological changes.

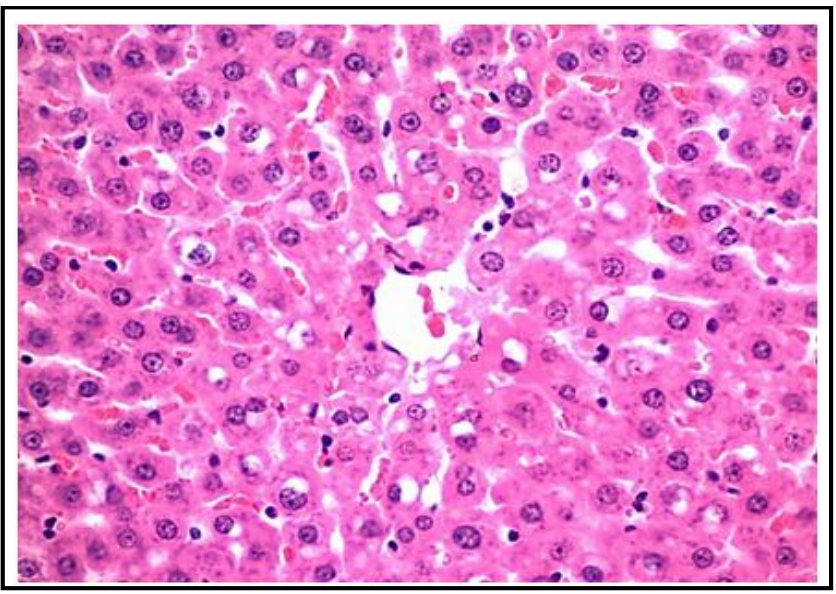

Plate 1: Microscopic view of liver in control group II showed normal architecture of hepatic acini $(\mathrm{H}$ and $\mathrm{E}$ stain $\times 480)$.

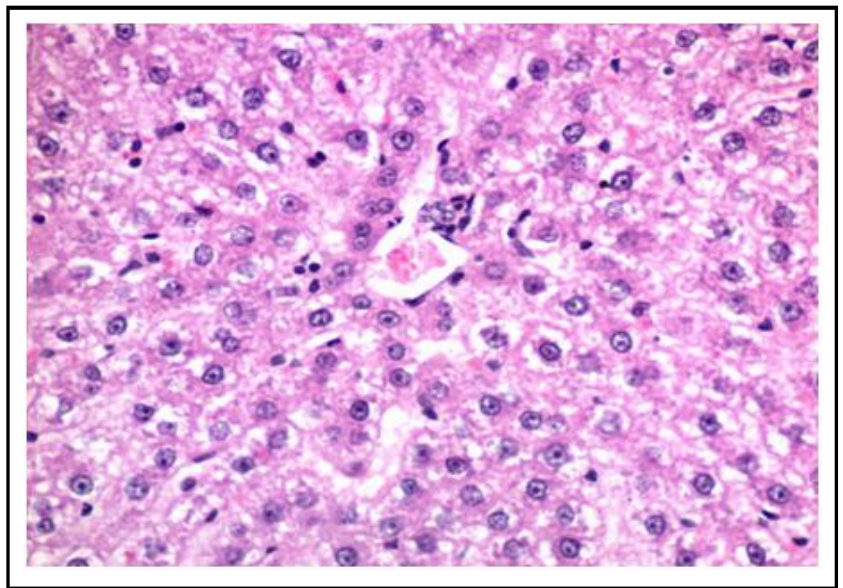

Plate 2: Microscopic view of liver in group III showed mild central vein congestion and vacuolar degeneration in hepatocytes compared to control group I $(\mathrm{H}$ and $\mathrm{E}$ stain $\times 480)$.

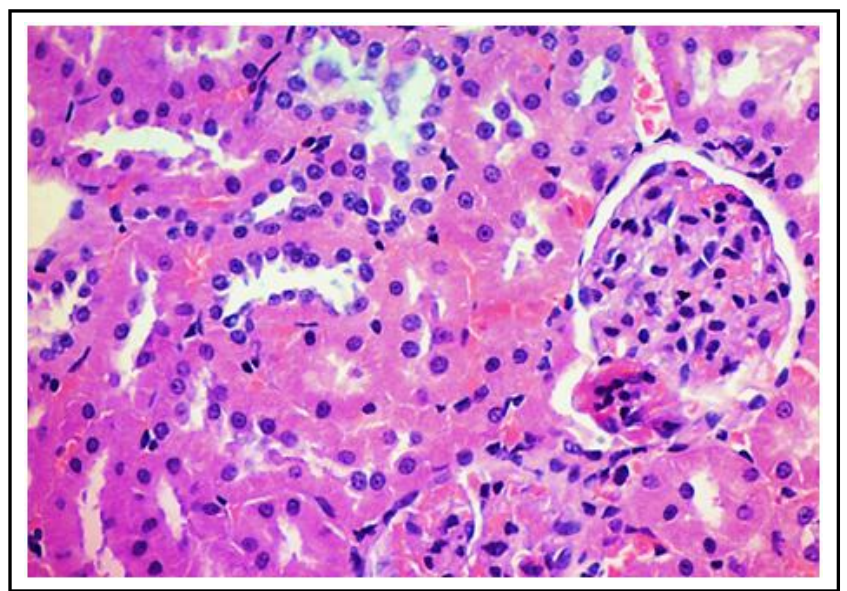

Plate 3: Microscopic view of kidney in group I showed normal architecture of renal tubular epithelium with normal intake glomeruli $(\mathrm{H}$ and $\mathrm{E}$ stain $\times 480)$.

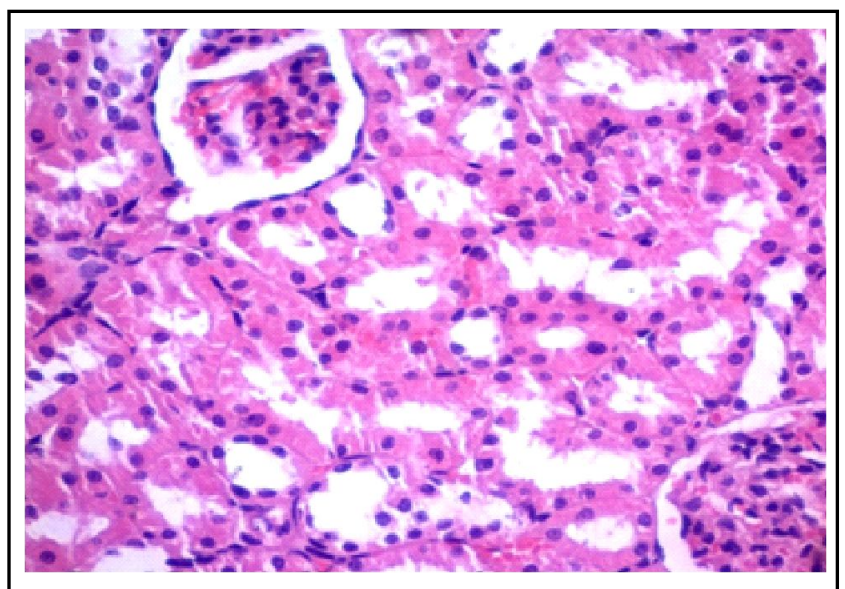

Plate 4: Microscopic view of kidney in group III showed normal architecture of renal tubular epithelium with normal intake glomeruli $(\mathrm{H}$ and $\mathrm{E}$ stain $\times 480)$. 


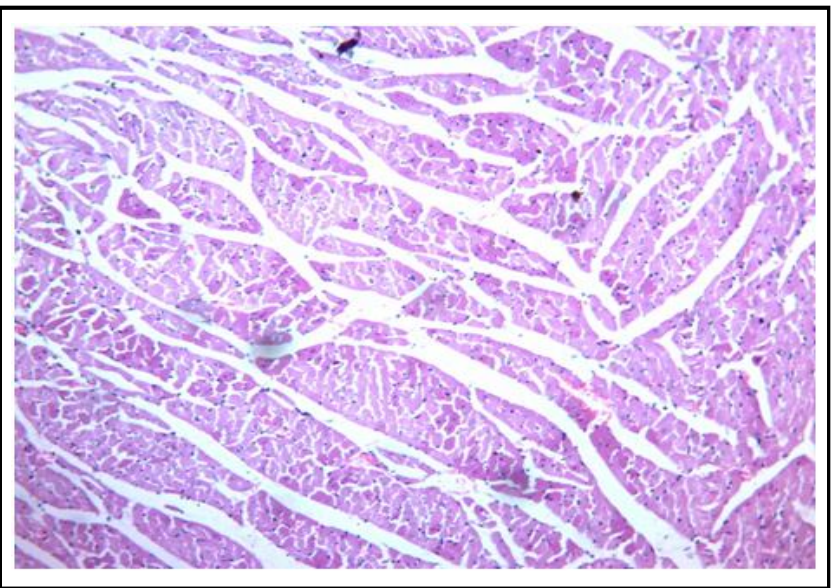

Plate 5: Microscopic view of heart in group I showed normal architecture of muscular bundles ( $\mathrm{H}$ and $\mathrm{E}$ stain $\times 240$ ).

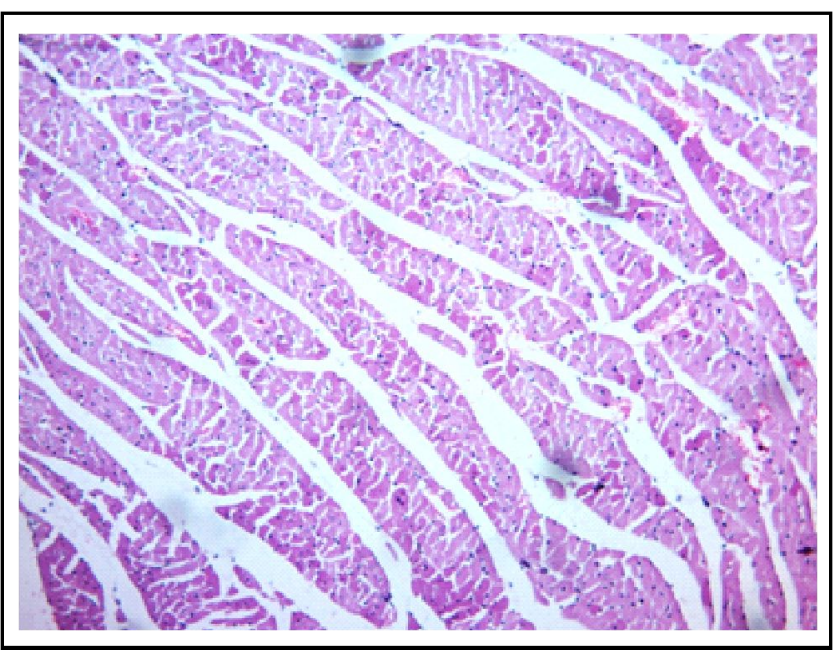

Plate 6: Microscopic view of heart in group III showed normal architecture of muscular bundles (H and E stain $\times 240$ ).

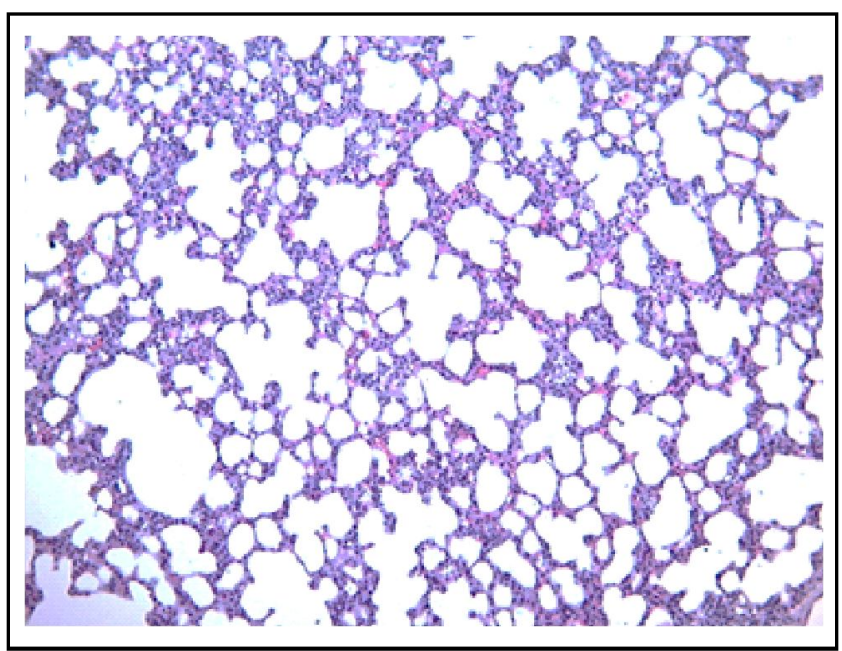

Plate 7: Microscopic view of lung in group I showed normal alveoli ( $\mathrm{H}$ and $\mathrm{E}$ stain $\mathrm{x} 240)$.

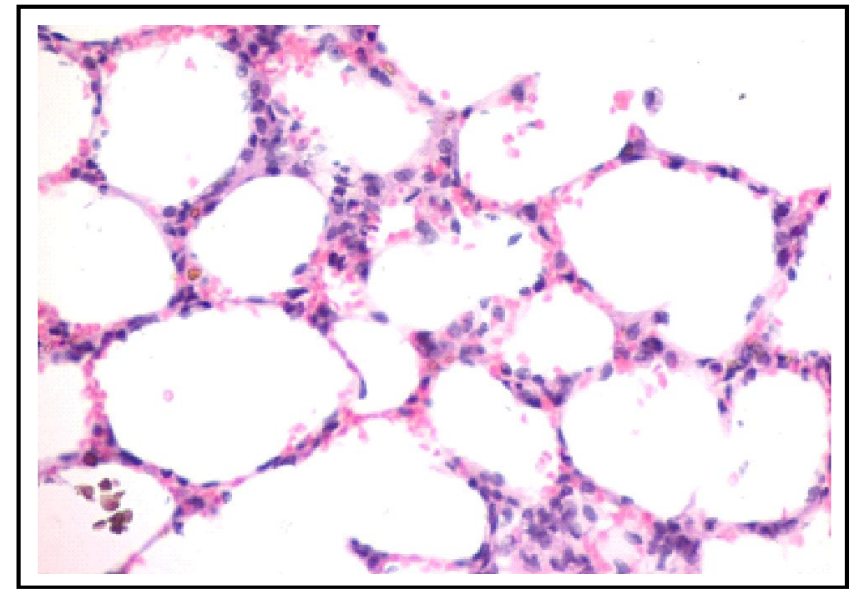

Plate 8: Microscopic view of lung in control group II showed normal architecture of lung alveoli ( $\mathrm{H}$ and $\mathrm{E} \times 480)$.

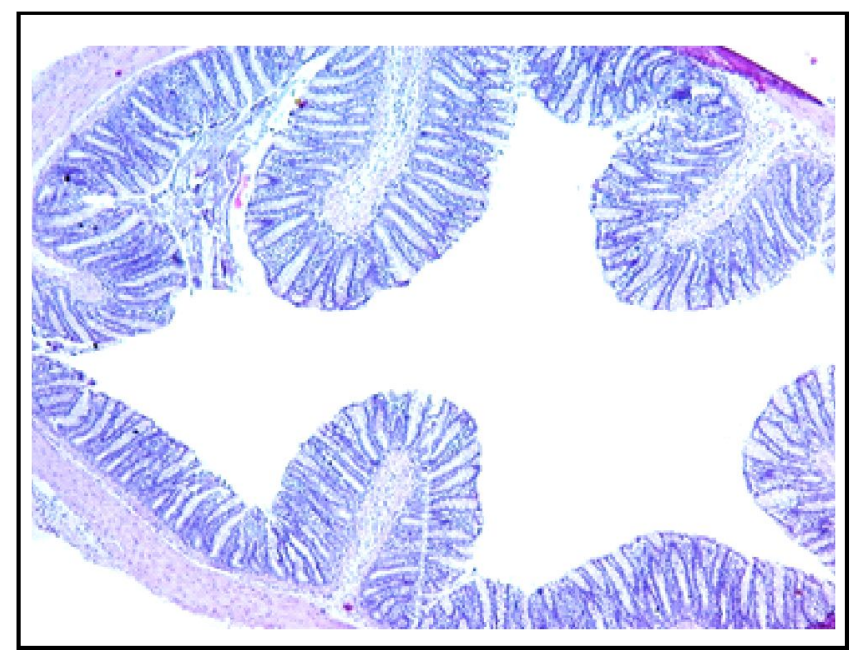

Plate 9: Microscopic view of intestine in group I showed normal intestinal villi $(\mathrm{H}$ and $\mathrm{E}$ stain $\times 240)$.

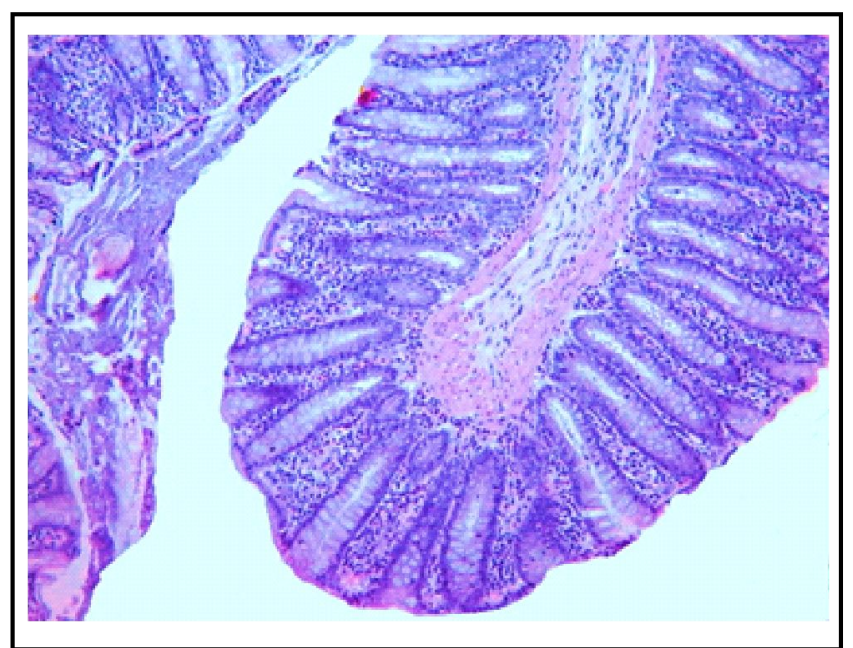

Plate 10: Microscopic view of intestine in group III also showed normal intestinal villi with intestinal epithelium $(\mathrm{H}$ and $\mathrm{E}$ stain $x$ 480). 


\section{Conclusion}

In conclusion, this study indicates the absence of significant pathophysiological alterations, following repeated oral administration of marbofloxacin alone and pretreated with piperine in rats. Piperine can be used with marbofloxacin which may not produce side effects of health consequence. These findings indicate that the natural active component like piperine may not reflect the safety concern parameters of the main drugs by diet-drug interactions. It may open a new path for insight into the approach for treatment of various diseases.

\section{Acknowledgements}

We are thankful to Junagadh Agricultural University for providing facility to carry out the study. Authors are thankful to Department of Veterinary Pathology, College of Veterinary Science and A.H., JAU, Junagadh for their help during the study.

\section{Conflict of interest}

The authors declare that no conflict of interest exists in the course of conducting this research. All authors had final decision regarding the manuscript and the decision to submit the findings for publication.

\section{References}

Ball, P.; Mandell, L.; Niki, Y and Tillotson, G. (1999). Comparative tolerability of newer fluoroquinolone antibacterial. Drug Safety, 21:407-421.

Bhadarka, D.H.; Patel, U.D.; Shaul, A.R.; Patel, H.B.; Modi, C.M. and Fefar, D.T (2018). Biochemical and histologic evaluation following multiple dose administration of paracetamol alone and along with polyherbal extract mixture in rats. Ann. Phytomed., 7(2):114-123.

Bhanot, S.K.; Singh, M. and Chatterjee, N. R. (2001). The chemical and biological aspects of fluoroquinolones: Reality and Dreams. Curr. Pharm. Des., 7:311-335.

Bhavsar, S.K.; Verma, M.P. and Thaker, A.M. (2004). Pharmacokinetics, tissue concentration and safety of multiple dose intravenous administration of ciprofloxacin in cow calves. Journal of Veterinary Pharmacology and Toxicology, 3(1):27-34.

Brown, S. A. (1996). Fluoroquinolones in animal health. Journal of Veterinary Pharmacology and Therapeutics, 19:1-14.

Chauhan, V.B.; Modi, C.M.; Patel, U.D.; Patel, H.B.; Kalaria,V.A.; Fefar, D.T.; Bhadarka, D.H.; Solanki, S.L. and Shaul, R.A. (2017). Safety profile of marbofloxacin following repeated intramuscular administration alone and piperine pretreated rats. Ann. Phytomed., 6(2):88-92.

Chunlaratthanaphorn, S.; Lertprasertsuke, N.; Srisawat, U.; Thuppia, A.; Ngamjariyawat, A.; Suwanlikhid, N. and Jaijoy, K. (2007). Acute and subchronic toxicity study of the water extract from dried fruits of Piper nigrum L. in rats. Journal of Science and Technology, 29(1): 109-124.

CPCSEA (2003). Committee for the purpose of control and supervision on experiments on animals. CPCSEA guidelines for laboratory animal facility. Indian Journal of Pharmacology, 35:257-274.
Ihrke, P. J.; Papich, M. G. and Demanuelle, T. C. (1999). The use of fluoroquinolones in veterinary dermatology. Veterinary Dermatology, 10:193204.

Khargharia, S.; Barua, C. C.; Nath, N. and Bhattachrya, M. (2007). Blood biochemical studies of enrofloxacin in repeated oral administration of yak after intravenous administration. Iranian Journal of Pharmacology and Theraputics, 6:137-138.

Kim, J. C.; Shin, D. H.; Ahn, T.H.; Kang, S.S.; Song, S.W.; Han, J.; Kim, C.Y.; Ha, C.S. and Chung, M.K. (2003). 26-week repeated oral dose hematological and biochemical parameters following toxicity study of the new quinolone antibacterial in Prague-Dawley rats. Food and Chemical Toxicology, 41(5):637-645.

Kumar, A. and Sharma, N. (2015). Comparative efficacy of piperine and curcumin in deltamethrin induced splenic apoptosis and altered immune functions. Pesticide Biochem. Physiol., 119:16-27.

Kumar, A.; Sasmal, D. and Sharma, N. (2015). Immunomodulatory role of piperine indeltamethrin induced thymic apoptosis and altered immune functions. Environ. Toxicol. Pharmacol., 39:504-514.

Lee, S.A.; Hong, S.S.; Han, X.H.; Hwang, J.S. and Oh, G.J. (2005). Piperine from the fruits of Piper longum with inhibitory effect on monoamine oxidase and antidepressant-like activity. Chem. Pharm. Bull., 53: 832-835.

Luna, L. G. (1968). Routine staining procedures. Hematoxylin and eosin stains. Manual of histologic staining methods of the Armed Forces Institute of Pathology. (McGraw-Hill, New York), $3^{\text {rd }}$ ed. pp:32-39.

Mahmood, M. and Hussein, A. (2013). Pharmacokinetics, pharmacodynamics and safety of marbofloxacin and trovafloxacin in sheep. Thesis at University of Queensland.

Mandell, L. and Tillotson, G. (2002). Safety of fluoroquinolones: An update. Can. J. Infect. Dis., 13:54-61.

Modi, C. M.; Ladumor, V. C.; Patel, U. D.; Patel, H. B.; Solanki, S. L. and Bhadarka, D. H. (2018). Phytochemical analysis and comparative study of in vitro free radical scavenging activity of different extracts of leaves of Abrus precatorius L. Ann. Phytomed., 7(2):133-137.

Modi, C.M.; Mody, S.K. and Patel, H.B. (2013a). Biochemical alteration induced after intramuscular administration of long acting moxifloxacin in sheep. Biochem. Pharmacol., 2:116.

Modi, C.M.; Mody, S.K. and Patel, H.B. (2013b). Hematological alteration induced after intramuscular administration of long acting moxifloxacin in sheep. Biochem. Physiol., 2:111.

Patel, H. B.; Patel, U. D.; Modi, C. M.; Shaul, A. and Solanki, S. L. (2018). Pharmacokinetic profiles of marbofloxacin following single and repeated oral administration in broiler chickens. Ann. Phytomed., 7(2):174-179.

Patel, J. H.; Varia, R.D.; Patel, U.D.; Vihol, P.D.; Bhavsar, S.K. and Thaker, A.M. (2009). Safety level of levofloxacin following repeated oral administration in white leg horn layer birds. Veterinary World, 2(4):137-139. 
Patel, J.A. and Shah, U.S. (2009). Hepatoprotective activity of Piper longum traditional milk extract on carbon tetrachloride induced liver toxicity in wistar rats. Caribe Plant Med. Aromat, 8:121-129.

Sadariya, K.A.; Gothi, A.K.; Patel, S.D.; Bhavsar, S. K. and Thaker, A. M. (2010). Safety of moxifloxacin following repeated intramuscular administration in wistar rats. Veterinary World, 3(10):449-452.

Sankar, P.; Telang, A.G. and Manimaran, A. (2012). Protective effect of curcumin on cypermethrin-induced oxidative stress in wistar rats. Exp. Toxicol. Pathol., 64:487-493.

Schalm, O. W. (1967). Veterinary Haematology, $2^{\text {nd }}$ Edn., Lea and Febiger, Philadelphia.

Shaul, A. R.; Patel, U.D.; Bhadarka, D.H.; Patel, H.B. and Modi, C. M. (2018) Modulation of antioxidant defense system by polyherbal extract mixture which ameliorated the pathophysiological alterations in streptozotocin induced diabetic rats. Ann. Phytomed.,7(2):102-113.

Shojaee, A.F. and Lees, P. (1997). Pharmacodynamic and pharmacokinetic inter-relationships of antibacterial drugs. Journal of Veterinary Pharmacology and Therapeutics, 20:14-17.

Snedecro, G.W. and Cochran, W.G. (1982). Statistical Methods, $8^{\text {th }}$ edn. Ames: Iowa State.

Spreng, M.; Deleforge, J.; Thomas, V.; Boisramé, B. and Drugeon, H. (1995). Antibacterial activity of marbofloxacin. A new fluoroquinolone for veterinary use against canine and feline isolates. Journal of Veterinary Pharmacology and Theraputics, 18(4):284-289.

Zhao, J.Q.; Du, G.Z.; Xiong, Y.C.; Wen, Y.F.; Bhadauria, M. and Nirala, S.K. (2007). Attenuation of beryllium induced hepatorenal dysfunction and oxidative stress in rodents by combined effect of gallic acid and piperine. Arch. Pharmacal. Res., 30:1575-1583.

Citation: Vipul B. Chauhan, Chirag M. Modi, Harshad B. Patel and Urvesh D. Patel (2019). Evaluation of pathophysiological alterations in rats with administered marbofloxacin alone and with piperine pretreatment. Ann. Phytomed., 8(1):178-184. 